\title{
On the market impact of wind energy forecasts
}

\author{
Jónsson, Tryggvi; Pinson, Pierre; Madsen, Henrik
}

Published in:

Energy Economics

Link to article, DOI:

10.1016/j.eneco.2009.10.018

Publication date:

2010

Document Version

Early version, also known as pre-print

Link back to DTU Orbit

Citation (APA):

Jónsson, T., Pinson, P., \& Madsen, H. (2010). On the market impact of wind energy forecasts. Energy Economics, 32(2), 313-320. https://doi.org/10.1016/j.eneco.2009.10.018

\section{General rights}

Copyright and moral rights for the publications made accessible in the public portal are retained by the authors and/or other copyright owners and it is a condition of accessing publications that users recognise and abide by the legal requirements associated with these rights.

- Users may download and print one copy of any publication from the public portal for the purpose of private study or research.

- You may not further distribute the material or use it for any profit-making activity or commercial gain

- You may freely distribute the URL identifying the publication in the public portal

If you believe that this document breaches copyright please contact us providing details, and we will remove access to the work immediately and investigate your claim. 


\title{
On the market impact of wind energy forecasts
}

\author{
Tryggvi Jónsson*,a,b, Pierre Pinson ${ }^{\mathrm{a}}$, Henrik Madsen ${ }^{\mathrm{a}}$ \\ ${ }^{a}$ DTU Informatics, Technical University of Denmark, Richard Petersens Plads, \\ building 321, DK-2800 Kgs. Lyngby, Denmark \\ ${ }^{b}$ ENFOR A/S, Lyngsø Allé 3, DK-2970 Hørsholm, Denmark
}

\begin{abstract}
This paper presents an analysis of how day-ahead electricity spot prices are affected by day-ahead wind power forecasts. Demonstration of this relationship is given as a test case for the Western Danish price area of the Nord Pool's Elspot market. Impact on the average price behaviour is investigated as well as that on the distributional properties of the price. By using a non-parametric regression model to assess the effects of wind power forecasts on the average behaviour, the non-linearities and time variations in the relationship are captured well and the effects are shown to be quite substantial. Furthermore, by evaluating the distributional properties of the spot prices under different scenarios, the impact of the wind power forecasts on the price distribution is proved to be considerable. The conditional price distribution is moreover shown to be non-Gaussian. This implies that forecasting models for electricity spot prices for which parameters are estimated by a least squares techniques will not have Gaussian residuals. Hence the widespread assumption of Gaussian residuals from electricity spot price models is shown to be inadequate for these model types. The revealed effects are likely to be observable and qualitatively similar in other day-ahead electricity markets significantly penetrated by wind power.
\end{abstract}

Key words: Electricity market, Spot prices, Wind power forecasts, Locally weighted polynomial regression, Conditional distributions

\footnotetext{
${ }^{*}$ Corresponding author

Email addresses: trjo@imm.dtu.dk/tj@enfor.dk (Tryggvi Jónsson), pp@imm.dtu.dk (Pierre Pinson), hm@imm.dtu.dk (Henrik Madsen)
} 


\section{Introduction}

Since the beginning of the nineties, electricity markets around the world have undergone drastic reforms, resulting in a more deregulated structure. The backbone of these changes has been the adoption of wholesale electricity markets, in which producers and distributors bid for purchase and sale of electricity. Commonly, these bids are placed through a central clearing mechanism which determines a spot price at which electricity is traded. However due to the complex nature of the commodity in question, the dynamics of these spot prices are only partially understood, making them difficult to accurately forecast. Nevertheless, understanding of the price dynamics (and the resulting increased predictability) is paramount for all market participants and regulators, for the purpose of planning, trading, risk management or alternatively market design (see e.g. Daneshi and Daneshi, 2008).

The complex nature of spot prices arises from numerous causes. First of all, anti-gaming policies along with the instantaneous nature of electricity and restrictions on its transmission make arbitrage over time and space nearly impossible (Boogert and Dupont, 2005; Sewalt and de Jong, 2003). Secondly, demand for electricity, seen from a shortterm perspective, is highly inelastic and has distinctive and complex characteristics in the first two moments, (see e.g. Taylor and McSharry, 2007 or Panagiotelis and Smith, 2008 and references therein). Thirdly, the electricity supply function is discontinuous, convex and steeply increasing at the high demand end (Nord Pool Spot AS, 2006a; Karakatsani and Bunn, 2008). In parallel, the presence of non-dispatchable renewable energy sources causes frequent variations in the shape of the supply function, due to their low marginal costs and potential prioritisation (Giabardo and Zugno, 2008). In addition, market design is generally complex and frequently changing support schemes for some plant technologies often lead to modifications of the market design as well. Finally, the oligopolistic structure in many markets has given rise to a debate about to what extent market power is exercised. Although controversial, evidence of market power being put to force has been documented on many major electricity markets (see e.g. Eggertsson, 2003; Schwarz et al., 2007; Christensen et al., 2007 and also Karakatsani and Bunn, 2008 for other sources). A main objective of the present paper is to demonstrate that wind power forecasts have an impact on the market, and to describe how they quantitatively affect prices on the electricity market. 
The combination of all the factors listed above results in a price behaviour unlike what is observed for most other traded commodities as the price time-series often exhibits periodicity, inter- and intra-day correlations, trends, mean reverting spikes, positive skewness and heavy tails (see e.g. Conejo et al., 2005; Panagiotelis and Smith, 2008; Kosater and Mosler, 2006, for empirical evidence of this). Furthermore, the increased emphasis on renewable energy sources around the world has made the dynamics of spot prices even more complex. The price characteristics have become more extreme and made prices even harder to predict - partly due to the very volatile nature of many of these energy sources.

Several papers have been dedicated to describing the short-term dynamics of electricity spot prices, either by (i) relying solely on previous values, i.e. in a univariate time-series modelling framework (Huisman et al., 2006; Conejo et al., 2005; Cuaresma et al., 2004), (ii) by accounting for the price's response to demand, fuel prices or weather conditions (Vehviläinen and Pyykkönen, 2005; Ruibal and Mazumdar, 2008; Mandal et al., 2006; Nogales and Conejo, 2006), or (iii) by using regime-switching approaches (Kosater and Mosler, 2006; González et al., 2005). However as correctly stated by Karakatsani and Bunn (2008), the models presented in those papers have a number of limitations. Firstly, fuel prices and weather conditions only affect the supply function indirectly and their influence on the elements of the supply function is highly non-linear. Therefore, those factors ought to be supplemented by, or transformed into, information that more directly affects the supply function and the behaviour of market participants in general, as suggested by Karakatsani and Bunn (2008) and Longstaff and Wang (2004). Secondly, most research works have been focused on daily averages or baseload/peakload averages which conceal to some or full extent the distinct intra-day variations of the prices. Recently, higher frequency analysis have appeared though (e.g. Huisman et al., 2006; Longstaff and Wang, 2004; Karakatsani and Bunn, 2008).

Operationally, energy produced by non-dispatchable energy sources is commonly bid into the markets using forecasts of the future production. In the case of wind power, production forecasting is a major and rapidly growing research field and has been the topic of countless papers (see e.g Giebel et al., 2003; Costa et al., 2008, for a state of the art review). Some efforts have been made to optimise the bidding of wind energy into deregulated electricity markets based on these forecasts, and in some cases on information about their situation-dependent 
uncertainty as well (Pinson et al., 2007; Matevosyan and Söder, 2006; Bathurst et al., 2002). These studies however have all regarded wind power as a price taker, and therefore not considered its potential effects on prices. Although this approach is suitable when concentrating on individual wind power generators, wind power as a whole is in fact a price maker as originally suggested by Skytte (1999) and Morthorst (2003), due to its extremely low marginal cost. In areas where wind power has a significant share in the generation portfolio, the most substantial shortterm changes in the global supply function arise from variations in wind power generation. As shown by Giabardo et al. (2009), estimated future wind power generation ${ }^{1}$ appears as a stochastic threshold in the supply function. The present paper presents an analysis of how electricity spot prices, for the case of the Western Danish price area (DK-1) of Nord Pool's Elspot market, are affected by wind power forecasts. The analysis puts emphasis on the effects of such forecasts on the mean behaviour of the prices, on the intra-day variations of these effects, as well as on the corresponding impact on the distributional characteristics of day-ahead electricity prices. Some studies have been presented on the effects of actual power generated by wind turbines on the spot prices in the area (Skytte, 1999; Morthorst, 2003; Moesgaard and Morthorst, 2008; Enevoldson et al., 2006) and they have shown this effect to exist - as also expected by economical arguments. However, these studies have been bounded to linear effects on the mean behaviour and have therefore neither captured the full extent of this impact nor any of the distributional effects. Furthermore, as the analysis are carried out on the actual measured power output they only show the presence of a relation between wind power generation and spot prices, rather than proving wind power to be a price maker on the market. Consequently, the resulting models can not be used for forecasting.

Showing wind power as a price maker in a short-term perspective, implies raising the question: "What will the electricity spot prices be, if it is believed that the wind will / will not blow?" As an answer to this question, the relationship between wind power forecasts and spot prices is shown not only to exist, but also to be highly non-linear and time dependent. Furthermore, it is demonstrated that the correlation between demand and wind power forecasts should not be neglected since it is

\footnotetext{
${ }^{1}$ And thereby wind power capacity due to the low marginal costs and sometimes prioritisation of wind power
} 
in fact the ratio between the forecasted wind power generation and the forecasted load that has the strongest association with the spot prices. In parallel, this proportional contribution of wind power to the supply is shown to have substantial influence on the distribution of the spot prices as well.

For the demonstration of these effects, a non-parametric regression model is employed. The relationship between forecasted wind power production and electricity spot prices is estimated for every hour of the day. This dependency is estimated by assuming that the relationship can be locally described with a second order polynomial. For estimation, a least squares criteria is employed allowing for the mean effect of forecasted wind power penetration on the prices to be extracted. Despite the facts listed about the (non-Gaussian) properties of the conditional spot price distribution, this approach serves well for estimating the mean behaviour of the spot prices, partially due to the non-linear properties of the model and the large amount of data used as input to analysis. Employing such a criteria for the non-parametric regression model prevents however from any inference on the effects of wind power forecasts on distributional properties of spot prices to be made. Therefore, the evaluation of these effects is performed by directly analysing the first four moments of the price distributions under different scenarios of the ratio between forecasted wind power and forecasted load. The wind power forecasts used are generated by WPPT ${ }^{2}$ (see Nielsen et al., 2002), a wind power forecasting tool that has been successfully used in Denmark over the past years and was used for bidding aid by almost every wind turbine owner in DK-1 during the period in question.

The remainder of the paper is structured as follows: Section 2 describes the market structure at Elspot and the data set used as input to the analysis. Section 3 provides a brief introduction to the mathematical approach to the modelling. In Section 4, an analysis of how the mean behaviour of the spot prices is affected by wind power forecasts is given, while the impact of these forecasts on the price distribution is the topic of Section 5. Finally, concluding remarks are given in Section 6 along with some general discussion.

\footnotetext{
${ }^{2}$ The Wind Power Prediction Tool
} 


\section{Nord Pool's Elspot}

\subsection{Market Setting}

The analysis presented in this paper is done on data from the Western Danish price area (DK-1) of Nord Pool's Elspot market. Elspot is a day-ahead physical delivery market for electricity. It is currently operating in the entire Scandinavia (Denmark, Finland, Norway and Sweden) and in the so called Kontek area, located in Northeastern Germany.

At Elspot, spot prices are set by a market equilibrium model, where supply and demand curves of all market participants are matched on a day-ahead basis. Gate closure is at noon each day for the period midnight to midnight in the following day and prices are published later in the day with a resolution of one hour. The one hour prices are calculated by matching the collaborative supply and demand curves, calculated from the bids and ask prices placed by the market participants (see Nord Pool Spot AS, 2006a,b, for details). This price, found from bids from all market participants, defines the system price from which the area prices are defined.

Due to transmission constraints, the region covered by Elspot is divided into several price areas. Physical constraints on transmission define the outer bounds of each price area, implying that transmission capacity within an area can be regarded as unlimited. The area spot prices are calculated in the same manner as the system price, but only considering the bids within the area along with possible utilisation of the transmission lines to surrounding areas (see Nord Pool Spot AS, $2006 \mathrm{~b}$, for details). The area prices, which determine at what price physical trading is done within an area, can therefore differ quite considerably between areas. If none of the interconnections between areas are fully utilised, the system price is valid in the whole region. However, this is seldom the case and therefore is modelling of the area spot prices appropriate when short term dynamics and forecasting are considered.

The DK-1 price area consists of Jutland, Funen and the islands west of the Great Belt. The area is an interesting context for investigation of electricity spot prices as it can be said to represent the future of liberalised electricity markets. This is because it has relatively large connections to its surrounding areas, and is heavily penetrated by an inexpensive, non-dispatchable energy source, i.e. wind power. In fact, DK-1 is currently the grid area in the world that has the largest share of wind power in its generation portfolio, with more than $20 \%$ of its annual consumption generated by wind turbines. 


\subsection{The Data}

The data, which the analysis here presented is carried out on, covers the period from January 4th 2006 to October 31st 2007. It consists of hourly area spot prices along with hourly consumption measurements for the area ${ }^{3}$ and wind power forecasts (in $M W$ ) with a temporal resolution of 15 minutes, made at 07:00 on the day before delivery for lead times up to 48 hours. The forecasts are made using WPPT (see Nielsen et al., 2002).

If the analysis is to be true to the criteria of analysing future electricity prices, both measures entering the wind power-load ratio have to be forecasts instead of actual measurements. When load forecasts are made using state of the art load forecasting models (e.g. Taylor and McSharry, 2007), the relationship between the actual load and the predicted load can be described as

$$
L_{t}=\widehat{L}_{t}+\varepsilon_{t} \quad \text { where } \quad \varepsilon_{t} \sim N\left(0, \sigma^{2}\right)
$$

where $L_{t}$ is the actual load, $\widehat{L}_{t}$ is the predicted load and $\sigma^{2}$ is the finite variance of the residuals, $\varepsilon_{t}$. Hence, by adding a Gaussian noise with the appropriate variance to the load measurements, a time series that has the characteristics of an actual load forecast series is obtained. The standard deviation of the noise is chosen as $2 \%$ of the average load for the period, since it reflects the performance of state of the art load forecasting models (see e.g. Taylor and McSharry, 2007). The use of simulated load forecasts gives rise to some deviations from the reallife situation though. First of all, the residuals of actual load forecasts are bound to have some autocorrelation in the lags up to the prediction horizon. This is not reflected in the simulated residuals. However, for forecasts of such a degree of accuracy as load forecasts are in general, the small prediction error is reflected by a small residual autocorrelation as well. The influence of the missing autocorrelation structure is therefore only marginal. Secondly, since both load forecasts and wind power predictions are typically based on weather forecasts, some correlation between the errors of the two might be observed in practise. This is however not the case when simulated forecasts are used since the computer generated noise, added to the load forecasts, is not correlated to the real error of the wind power predictions. The error of the

\footnotetext{
${ }^{3}$ Available at http://www.energinet.dk/en/menu/Market/Market.htm and at http://www. nordpoolspot.com
} 
wind-load forecasting ratio will therefore have characteristics that differ slightly from what would be observed if both were actual forecasts. Nevertheless, the mean of the errors will still be zero in both cases and other effects are minor. These potential dissimilarities from the practical situation are ignored in the analysis to follow due to their small impact on the results.

Hourly wind energy forecasts in $M W h$ also have to be derived. This is done by linearly interpolating between each two adjacent forecasts in every hour and taking the result as the production in $M W h$ for that 15 minute period. These interpolations are then summed up for each hour. So in mathematical terms, an hourly forecast is obtained by

$$
\widehat{V}_{t}^{(h)}=\sum_{i=2}^{5} 0.25 \cdot\left(\frac{\widehat{V}_{t, q(i-1)}^{(q)}+\widehat{V}_{t, q(i)}^{(q)}}{2}\right)
$$

where $\widehat{V}_{t}^{(h)}$ (hereafter noted as $\widehat{V}_{t}$ ) is the hourly wind energy forecast for hour $\mathrm{t}$, and $\widehat{V}_{t, q(i)}^{(q)}$ is the 15 minute wind power forecast for quarter $i$ within hour $t$.

In order to account for the correlation between demand and wind power forecasts, the wind power penetration level, $\widehat{V}_{t}^{(p)}$, is defined as

$$
\widehat{V}_{t}^{(p)}=\frac{\widehat{V}_{t}}{\widehat{L}_{t}}
$$

Finally, it should be emphasised that no extreme events are excluded from the data set.

\section{Non-parametric regression modelling of day-ahead electric- ity prices}

The relationship between, area spot price and wind power generation is far from being linear. It is therefore essential for obtaining a proper estimate of the effects of wind power forecasts on the area spot price to account for these non-linearities. The problem of estimating a complex non-linear relationship between variables is however not a trivial one. But by assuming that the relationship is locally linear or locally describable by a low order polynomial the problem is much more convenient to deal with. One could locally solve a weighted least squares problem as described in detail for the general case in (Cleveland and Devlin, 1988; Nielsen et al., 2000; Madsen and Holst, 2000). 
Let a model for the spot prices at time $t, P_{t}$, be defined as

$$
P_{t}=\boldsymbol{\theta}\left(\boldsymbol{x}_{t}\right)+\varepsilon_{t},
$$

where $\theta(\cdot)$ is a vector of coefficient functions and $\varepsilon_{t}$ is a noise term. Furthermore, $x_{t}$ is a vector of explanatory variables. In this case those variables are some direct or derived form of a wind power forecast, $\widehat{V}_{t}$, and an hour of the day indicator, $k_{t}$.

The functions $\theta(\cdot)$ are estimated at a number of distinct points by approximating the functions using polynomials and fitting the resulting linear model locally to each of these fitting points. More specifically, let $U=\left[\begin{array}{ll}\widehat{V}_{U} & k_{U}\end{array}\right]^{T}$ denote a particular fitting point, chosen from a set of $m$ total fitting points, and let $p_{2}(\boldsymbol{U})$ be a column vector of terms in the corresponding $2 n d$-order polynomial, i.e.

$$
p_{2}(\boldsymbol{U})=\left[\begin{array}{llllll}
1 & \widehat{V}_{U} & k_{U} & \widehat{V}_{U}^{2} & \widehat{V}_{U} k_{U} & k_{U}^{2}
\end{array}\right]^{T} .
$$

Furthermore, let $\phi_{U}=\left[\begin{array}{lll}\phi_{U, 1} & \ldots & \phi_{U, 7}\end{array}\right]^{T}$ denote the coefficient vector at $U$. Now the linear model

$$
P_{U}=p_{2}(\boldsymbol{U})^{T} \boldsymbol{\phi}_{U}+\varepsilon_{U}
$$

can be used to describe the spot price in the close vicinity of $U$ and can be fitted locally using weighted least squares (WLS), i.e.

$$
\widehat{\boldsymbol{\phi}}(\boldsymbol{U})=\underset{\phi_{U}}{\arg \min } \sum_{i=1}^{N} w_{U}\left(\boldsymbol{x}_{i}\right)\left(P_{i}-x_{i}^{T} \phi_{U}\right)^{2}
$$

where $x_{i}=p_{2}\left(U_{i}\right)$ and for which a unique closed-form solution exists provided that the matrix with rows $x_{i}$ corresponding to non-zero weights has a full rank. The weights are assigned as

$$
w_{U}\left(x_{i}\right)=W\left(\frac{\left\|x_{i}-x\right\|_{2}}{h(x)}\right)
$$

where $W(\cdot)$ is a decreasing weight function taking non-negative arguments. Furthermore, $h(x)$ is the bandwidth used for the particular fitting point, i.e. the maximum euclidean distance between a fitting point and an observation resulting in a non-zero weight being assigned in Eq. (7). This implies that a small bandwidth will result in a very flexible model with low bias and high variance while applying a large bandwidth yields a more rigid model having higher bias but lower variance. 
For readers familiar to exponential smoothing, applying a small bandwidth corresponds to having a low level of smoothing in the model. The bandwidth can therefore be said to be a scalar controlling the rate at which the weight of an observation, in the estimation, decreases with distance from the fitting point. From this it follows that the argument which $W(\cdot)$ takes is the relative distance between the fitting point and the other point falling within the bandwidth. Following Cleveland and Devlin (1988) and Nielsen et al. (2000), a tri-cube kernel is chosen as a weight function so

$$
W(u)=\left\{\begin{array}{ll}
\left(1-u^{3}\right)^{3} & u \in[0,1) \\
0 & u \in[1, \infty)
\end{array} .\right.
$$

Turning back to the global view on the model, it can be seen that for an arbitrary chosen $U$, out of a set of $m$ fitting points, there can be found a parameter vector $\phi_{U}$. From these, the elements of $\theta\left(x_{t}\right)$ are estimated as

$$
\widehat{\boldsymbol{\theta}}\left(\boldsymbol{x}_{t}\right)=\widehat{\boldsymbol{\theta}}\left(\boldsymbol{p}_{2}\left(\boldsymbol{U}=\boldsymbol{x}_{t}\right)\right)=\boldsymbol{p}_{2}^{T}(\boldsymbol{U}) \widehat{\boldsymbol{\phi}}(\boldsymbol{U})
$$

where $\widehat{\phi}(\boldsymbol{U})$ is the WLS estimate of $\phi_{U}$.

The bandwidth, $h(x)$ is chosen so that at any given time $30 \%$ of all observations fulfil $\left\|x_{i}-x\right\|_{2} \leq h(x)$. In other words, the bandwidth is varied according to the local density of the data by letting $h(x)$ be equal to the distance of the $q$ th-nearest $x_{i}$ to $x$, where $q$ is $30 \%$ of the total number of observations (see e.g. Cleveland and Devlin, 1988, for details). The choice of the criteria that $30 \%$ of the observations should fall within the bandwidth is made since it was desired to obtain as local estimates as possible and $30 \%$ was the smallest bandwidth that resulted in a full rank design matrix at all times. This criteria is applied for estimation in all $m=24^{2}$ fitting points.

Despite what has been stated previously in this paper regarding the conditional distribution of the spot prices, using this sort of least squares technique is deemed suitable for this analysis. This is because the model is only used for assessing the average dependency between the variables and for such estimates, Gaussian estimators are generally known to be the best ones for most types of data. Furthermore, the non-Gaussianity of the residuals is reduced by the model's non-linearity. This aside, as will be demonstrated later on in the paper (Figure 5), despite the prices not being normally distributed, their distribution has a bell shaped form, making the Gaussian assumption not completely 
inappropriate. In addition, the analysis is carried out on a very extensive data set containing hourly observations for 22 consecutive months. Therefore, will the impact of each individual extreme only be minimal. Hence, the use of robust least squares or similar techniques is not necessary.

How the method is applied in the analysis to follow can be summarised as follows. First the data is scaled so all variables are between $[-1,1]$. Then a grid of $m=24 \times 24$ equidistant fitting points is defined.

For each of these fitting points, $\boldsymbol{U}_{m_{i}}$, the following steps are taken:

1. Calculate the euclidean distances between every observation and the fitting point of interest. Applying the bandwidth principle previously described, these distances are normalised by that corresponding to the $q$ th-nearest neighbour, where $q$ is set to $30 \%$, and thereby form the input to Eq. (9).

2. Compute the estimate $\hat{\Phi}\left(\boldsymbol{U}_{m_{i}}\right)$ of the local polynomial coefficients at the fitting point $\boldsymbol{U}_{m_{i}}$ by solving Eq. (7).

3. Obtain the local estimate of the spot price at $\boldsymbol{U}_{m_{i}}$ from Eq. (10) with $p_{2}\left(\boldsymbol{U}_{m_{i}}\right)$ as the polynomial for the particular fitting point as described by Eq. (5).

The mean spot price for any point $U$ can be obtained by bilinear interpolation from the local estimates calculated at each fitting point. This finally yields a smooth trend surface like those shown and commented on in the following.

\section{General trend: the effect of forecasts on the mean price}

On a day-ahead basis, the area spot price is subject to a considerable uncertainty. It can therefore rightfully be stated that the future spot price has some unknown distribution and the model presented in the previous section can be used, if applied correctly, to provide information about the mean in this distribution.

In Figure 1 the average spot price in DK-1 is estimated as a function of both the time of the day and the forecasted wind energy production measured in $M W h$ per hour. From the figure, it is quite obvious that forecasts of large wind power production in a given hour will, on average, result in a lower spot price in that hour, since when going along the wind power-axis, in the increasing direction, the mean price decreases. 


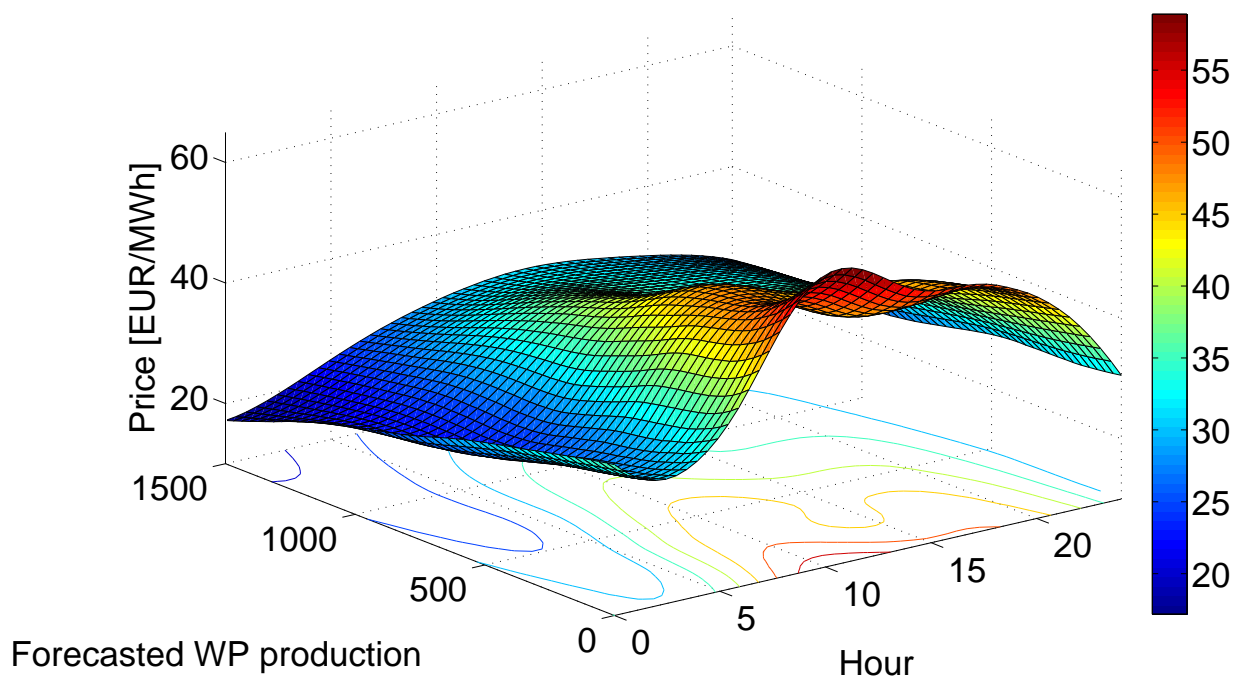

Figure 1: The dependence of the spot prices on forecasted wind power production and its variation throughout the day

During the night, the average price varies from around $30 € / M W h$ for a forecasted low wind power production down to around 18€/MWh for the hours with forecasted large wind power production. During the day, this difference between the two extremes in forecasted quantities of wind power produced is somewhat larger as the prices go from around $50-55 € / M W h$ down to around $30 € / M W h$. Due to the infrequent occurrence of the installed wind power capacity being fully utilised, the wind power-axis only reaches $1500 \mathrm{MWh}$ which is somewhat lower than the full utilisation ${ }^{4}$. Observations above the $1500 \mathrm{MWh}$ limit are nevertheless used for estimation when it is relevant.

What is also very interesting is that the daily price raise, during the hours of the day where consumption reaches its daily peak, evens out as wind power production in the system increases. The reason for this is that the virtually nil marginal cost of the wind turbines shifts the supply curve to the right when more wind power is produced and therefore it takes more consumption to reach the steep end of it. In other

\footnotetext{
${ }^{4}$ Installed wind generation capacity in DK-1 was around $2400 \mathrm{MW}$ during the considered period.
} 
words, the increased production of the turbines means that less cost efficient plants otherwise covering the base load, will be covering the peaks only. This in turn prevents the even less cost efficient generators from being utilised during the hours when demand peaks.

As stated earlier, the demand for electricity varies severely throughout the day and the week. The same quantity of wind power, measured in $M W h$, can therefore have quite different effects on the price depending on the time of the day and the week. More specifically, electricity demand is generally lower during the evening and the night and therefore will a large volume of wind power produced in these hours make up for a larger share of the total demand than the same quantity would do during the day. This in turn will cause the equilibrium point of the supply and demand curves to be placed lower during the evening and the night than it would during the day. In order to eliminate these effects, to some extent at least, the wind power forecasts can be included as the proportional contribution to the total supply instead of its absolute contribution. In other words, by substituting the forecasted wind power production, $\widehat{V}_{t}$, with the forecasted wind power penetration defined in Eq. (3), $\widehat{V}_{t}^{(p)}$, a better prediction of the price equilibrium is gained from the wind power forecasts.

There are certainly other ways of deriving a number representing the interaction between wind power predictions and load forecasts. For instance, the difference between the forecasts could be considered instead of the ratio between the two. Although the relationship will then appear differently, simulations indicate that the extent of the impact will be approximately the same. It is also intuitively appealing to work with values that are between 0 and 1 . Therefore, further analysis is only presented on $\widehat{V}_{t}^{(p)}$ as it is defined in Eq. (3).

In Figure 2 a smooth estimate of the spot price, as a function of the time of the day and forecasted wind power penetration, is given. The figure shows the same type of effects as described before. However, the effects are more dramatic than seen in Figure 1 since the same actual production now has different effects depending on what time of the day and the week ${ }^{5}$ the production occurs. The average spot price is again considerably lower at times where wind power production has been predicted to be large. The difference between the two extremes in forecasted production is roughly the same during night hours, while

\footnotetext{
${ }^{5}$ Due to the weekly variation in the load
} 


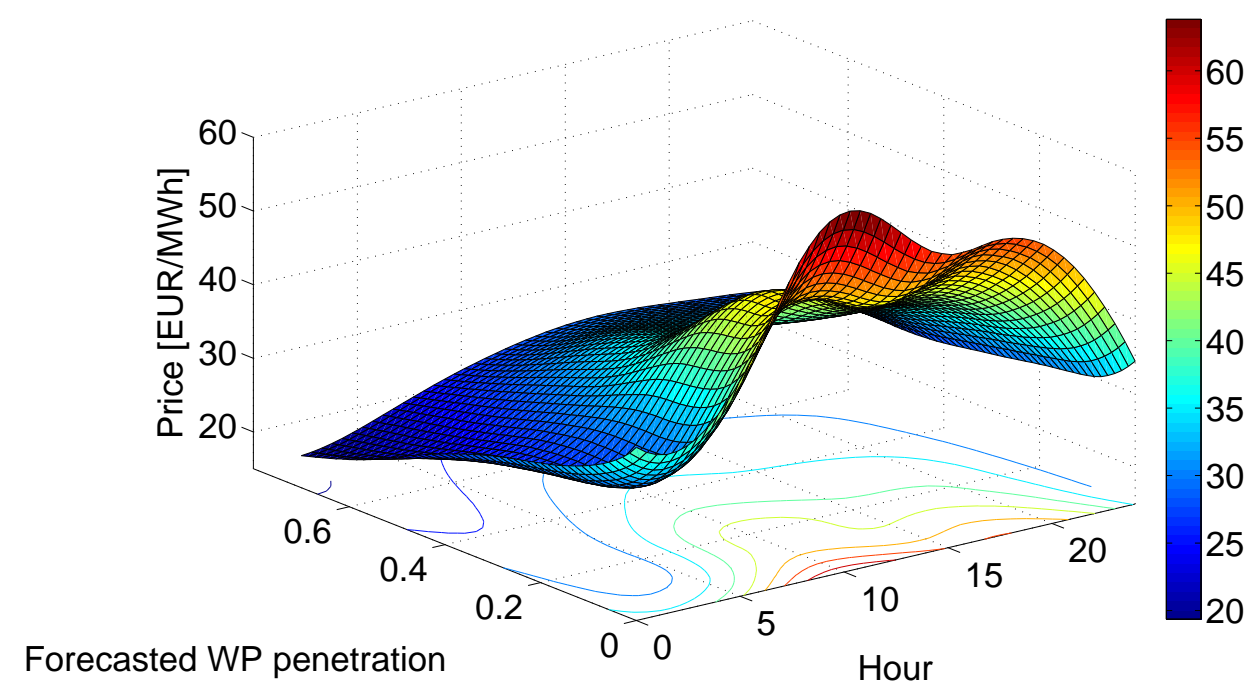

Figure 2: The dependence of the spot prices on forecasted wind power penetration and its variation throughout the day

the difference has increased during the day. During the day, the average spot price is around $55-60 € / M W h$ when nothing of the demand is supplied by wind power. The average prices then rapidly diminishes with a small increase in wind power penetration, and after a short stand still as the penetration approaches $20 \%$, the sharp decline continues up to around $40 \%$ predicted penetration, for which the average spot price is around $35 € / M W h$. When the forecasted wind penetration has reached $40 \%$, a decrease in average price per penetration percent becomes more subtle and as the forecasted wind power penetration reaches $80 \%$, the average spot price has declined to around $22-25 € / M W h$.

Some general information about the characteristics of the supply function can also be deduced from the figure. The rather sharp gradient changes in the average price in the lower penetration end of the plot are a clear indication of the discontinuity of the supply function. Wind power quickly pushes the steepest end of the supply curve to the right side of the equilibrium point, and thereby out of the generation portfolio for that hour, explaining the sharp decline in the average price. After stabilising itself, the average price decreases rapidly again when another threshold is pushed out of the equilibrium. The final subtle decline, and the night time behaviour can also be explained by considering 


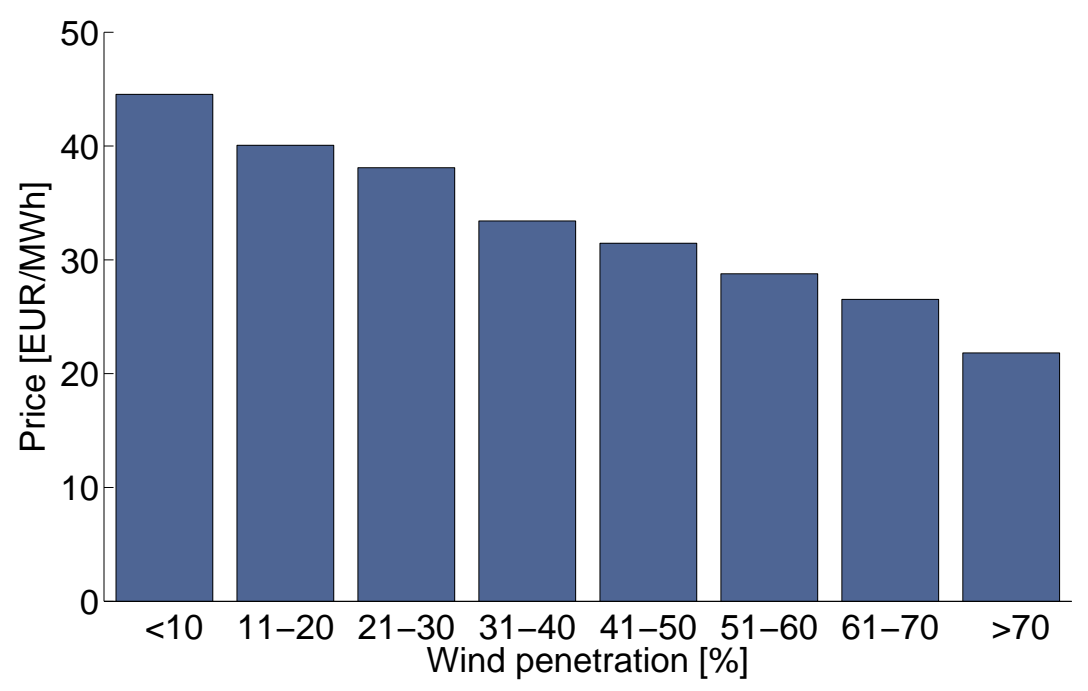

Figure 3: Average spot price, categorised by intervals of forecasted wind power penetration, in DK-1 in the period January 4th 2006 - October 31st 2007

the shape of the underlying supply function, since the equilibrium point has then reached the flatter part of the supply function where cheaper energy sources such as Norwegian hydro power and wind power are placed.

Even though it is clear from Figure 2 that forecasted wind power does in fact influence the spot prices, it is hard to point out how big the actual effects are. In Figures 3 and 4 the extent of the effects are better illustrated. In Figure 3 the average spot price is shown for predicted wind power penetration on certain intervals in the period which the data set spans. It shows how the average spot price generally decreases as the share of wind power in the system increases.

In Figure 4, the impact of forecasted wind power penetration is formulated in terms of reduction in price compared to no wind being present in the system. For doing this, the assumption is made that wind power penetration under $4 \%$, corresponding to a production of approximately $80 \mathrm{MWh}$ per hour, has very little or no effects on the spot prices. Observations falling on this interval are taken as a reference point and represents the situation when no wind power is predicted to enter the system. Comparing the average spot price for the reference group, which is $€ 44.43$, to that of the remaining observations, where the average is $€ 36.68$, shows that the spot prices drop on average by $17.5 \%$ when the 


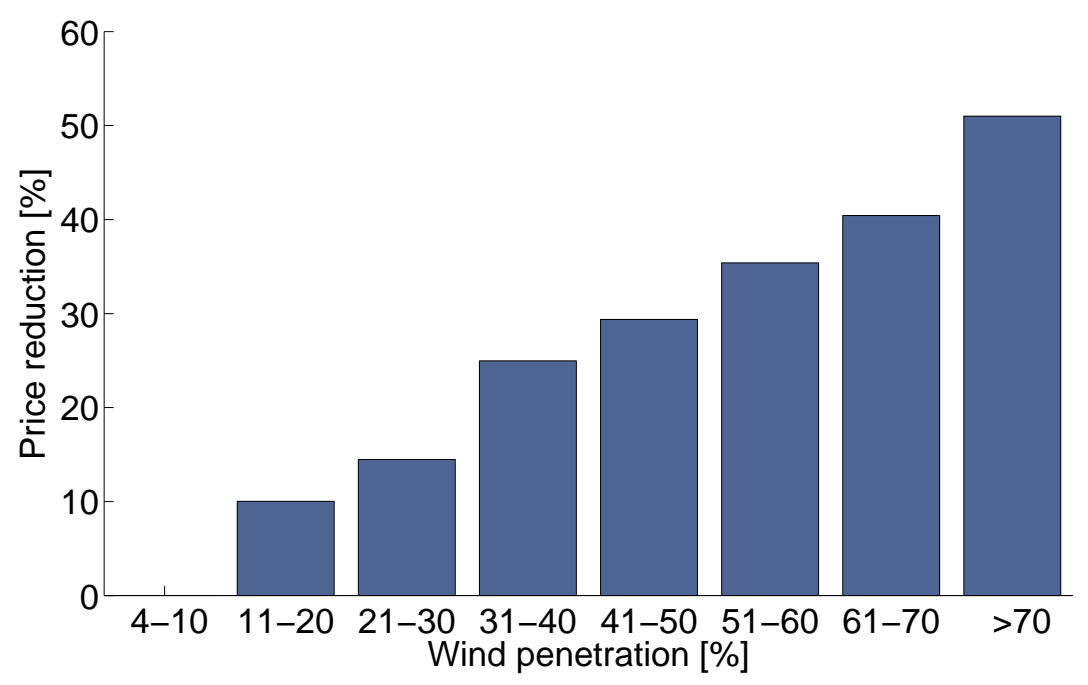

Figure 4: Reduction in average spot price, compared to the "no wind" situation, for different levels of forecasted wind power penetration in DK-1 in the period January 4th 2006 - October 31st 2007

forecasted wind power penetration exceeds $4 \%$. In Figure 4, the penetration levels above $4 \%$ have been divided into intervals of $6-10 \%$ and the bars represent how much lower on average, the price is during periods of the given penetration interval, compared to the reference "no wind" situation. The plot clearly illustrates that the spot prices tend to decrease as the forecasted wind power penetration increases.

The extent and the characteristics of the effects that have been shown to exist here indicate that properly accounting for them will be of serious help when electricity spot prices are to be forecasted in an area penetrated by wind power to some or large extent. These effects are consistent with what intuitively would be expected and would provide a forecasting model with vital information about the current shape of the supply function and thereby a good indication about the equilibrium point. However although the existence of these effects is undisputed, it can be debated whether they are for the good or worse, now when the share of wind power stands to be increased all over the world. Less expensive electricity might sound appealing for many at first, especially put in context with marginal bidding. On the other hand, this results in less contribution to the enormous initial investments of power plants of any kind. This will in turn reduce investors' interest in investing in new 
plants. Furthermore, lower electricity prices pose a threat to the existence of flexible power plants that produce electricity at high marginal costs. These plants however contribute heavily to a much needed stability in the energy supply.

\section{Effects of wind power forecasts on price distributional prop- erties}

Having established that forecasted wind power penetration certainly affects the mean spot price in DK-1, the question remains whether it affects the distribution of the prices as well. Equipped with more comprehensive knowledge about the relationship between price volatility and one or more of its fundamental causes (in this case wind power forecasts), one may better explain and hereby estimate future volatility levels while conditioning it upon these causes, e.g. in a non-parametric fashion. For carrying out the distribution analysis, the data set is divided into bins, according to forecasted wind power penetration, so that approximately 2500-3000 observations belong to each segment. Then the properties of the price distribution are estimated within each bin.

In Figure 5, histograms of the electricity prices are shown for different levels of forecasted wind power penetration. The figure illustrates, what already has been established, that the mean price shifts towards zero as forecasted wind power penetration increases. Furthermore, the positive skewness of the price distribution is quite evident from the figure as well as the fact that the heavy tail diminishes with increased forecasted wind power penetration. This translates to the statement that the probability of extremely high prices is much lower when the wind power penetration is predicted to be high.

The difference in distribution properties is summarised in Table 1. The first two lines in the table show the shift of mean, already dis-

Table 1: Properties of the spot price distribution for different scenarios of forecasted wind power penetration

\begin{tabular}{lcccccc}
\hline & $0-5 \%$ & $5-10 \%$ & $10-16 \%$ & $16-25 \%$ & $25-40 \%$ & $40-100 \%$ \\
\hline Mean & 42.98 & 41.13 & 40.26 & 38.10 & 33.24 & 26.02 \\
Std. Dev. & 16.95 & 15.32 & 14.18 & 13.08 & 11.35 & 11.23 \\
Skewness & 0.82 & 0.48 & 0.39 & 0.63 & 0.32 & 0.29 \\
Kurtosis & 4.41 & 3.39 & 3.40 & 4.05 & 3.04 & 4.09 \\
\hline
\end{tabular}



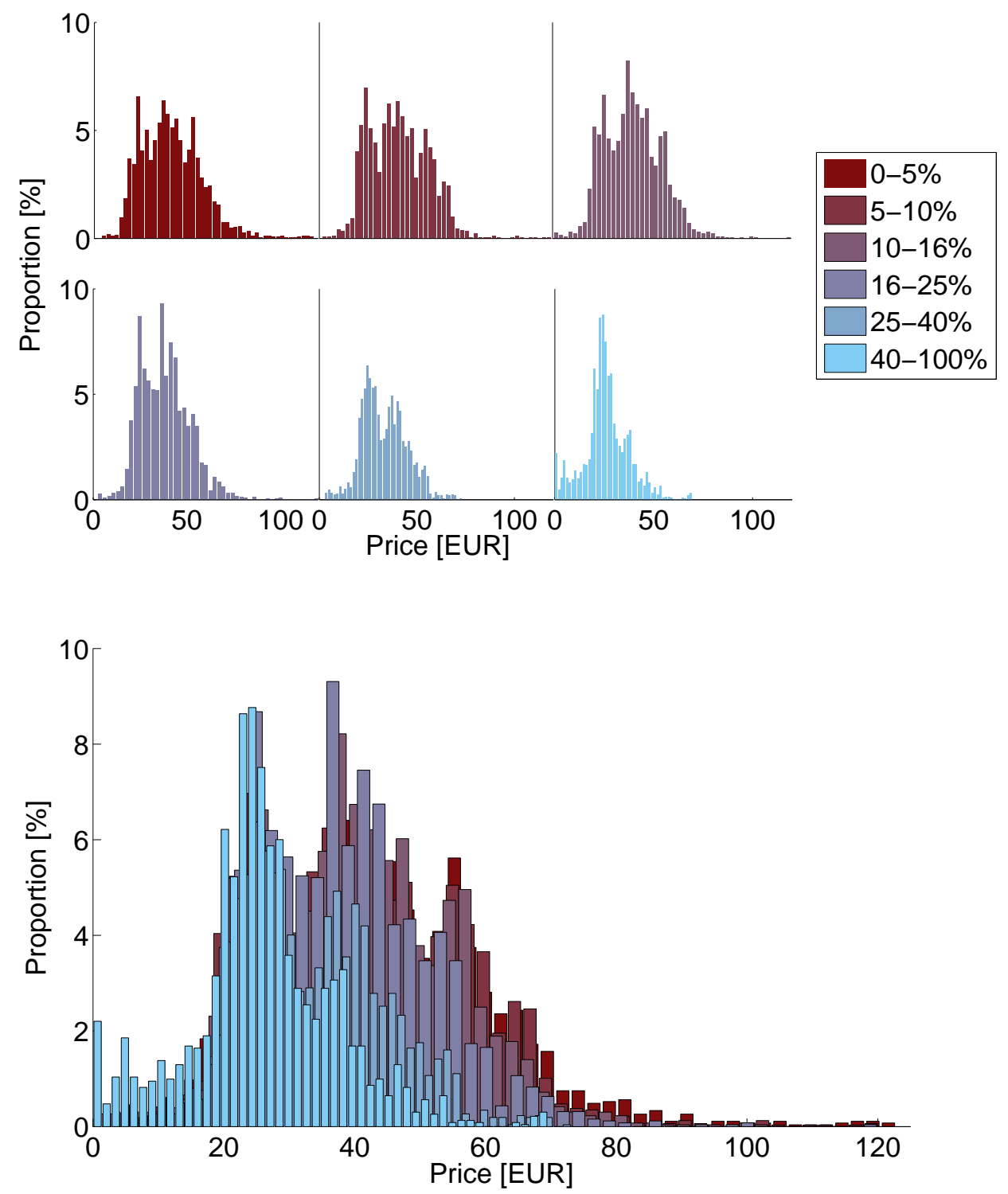

Figure 5: Distribution of prices for different intervals of forecasted wind power penetration 
cussed, and reduction in standard deviation, indicating less volatility of the prices. Lines 3 and 4 show how the skewness and kurtosis of the distributions change for the different levels of penetration. Despite the fact that no obvious pattern is detectable in lines 3 and 4, they represent quite dissimilar distributions. Taking the penetration intervals from left to right in the table, the first distribution is rather skewed and with high kurtosis, due to the heavy tail seen in Figure 5. Then as the wind power penetration increases in the 2nd and 3rd intervals, the tail becomes not as heavy, while the mean does not shift all that much, explaining the decrease in both skewness and kurtosis. When the penetration reaches the level of the 4th interval, the mean has shifted more while the rather high prices still occur. Hence, the increase in skewness and kurtosis. For predicted wind power penetration between 25-40\% these extreme price situations no longer occur, reflected in a decrease both in skewness and kurtosis. This threshold effect is yet another nonlinear effect introduced in the market by wind power or wind power forecasts. Finally, for the highest forecasted penetration interval, the frequency of very low prices increases substantially, explaining the reduction of skewness and increase in kurtosis. So to summarise, going from a low wind power penetration to high, generally leads to a lower skewness due to the diminishing frequency of very high prices along with the increased probability of very low prices.

Another thing that catches the eye in Figure 5 is the relatively high proportion of prices equal to zero in the histogram representing the highest penetration interval. Over $2 \%$ of the times when wind penetration is above $40 \%$, electricity spot prices are $0 € / M W h$. Although ill-detectable from the figure, this situation rarely occurs for the 25 $40 \%$ penetration interval, while it does not occur for the lower levels of penetration. For the four lower ones, the minimum price does however approach zero as the forecasted penetration increases. The occurrence of the spot price being $0 € / M W h$ will result in a negative cash flow for producers subject to imbalance costs in that hour. In other words, it will pay off, even for producers with no marginal production costs, not to produce electricity. This further supports what was stated at the end of previous section about the down side of increased wind power penetration under current market conditions.

From a modelling perspective, the dissimilarity of the spot price distribution between different levels of forecasted wind power penetration strongly indicates that estimating prediction intervals conditioned on the wind power predictions is worth the effort. It is quite obvious 
that the spot prices are not Gaussian distributed and therefore it must be deemed highly unlikely that models constructed with least squares techniques will have Gaussian residuals. Prediction intervals for such models should therefore be estimated using other techniques. In fact the distributions are so far from parameterised distributions that it seems reasonable to conclude that non-parametric approaches, like for instance quantile regression (Møller et al., 2008), will return the most reliable prediction intervals.

\section{Conclusions and Discussion}

The analysis presented in this paper demonstrates the dramatic impact of predicted wind power penetration in the system on not only the level of the spot prices but also their distributional characteristics. The spot price is, on average, shown to decrease with increased predicted wind power penetration, while intra-day price variations diminish to some extent. As all this happens in a non-linear manner, the use of the non-parametric regression model for the analysis proves to be very beneficial. Furthermore, wind power forecasts are shown to cause threshold effect in the price behaviour, with e.g. the appearance of zero prices, or the removal of extreme prices. They could therefore contribute to an understanding of some of the non-linearities and regime-switching behaviour in the prices. The results of this paper therefore support some of the conclusions of Karakatsani and Bunn (2008) such that aspects of plant dynamics should be considered when models of the short-term dynamics of electricity spot prices are to be derived. It would therefore be interesting to derive a forecasting model for these prices that accounts for the impact of forecasted wind-to-load ratio (see e.g. Jónsson, 2008). When developing such an approach, accounting for the uncovered non-linearities in the relationship between forecasted wind power penetration and day-ahead electricity prices will be essential.

The findings of this paper confirm what previous studies of the impact of wind power on electricity spot prices have shown, that wind power has a non-negligible impact on day-ahead electricity prices. Here however, based on the claim that it is instead the predicted wind power penetration that should be seen as an explanatory variable, the impact is shown to be more substantial than previously recorded (Enevoldson et al., 2006; Moesgaard and Morthorst, 2008). The corresponding relationship moreover turns out to be highly non-linear, and the distributional characteristics of prices are also affected. The results also show 
that a simple assumption like Gaussianity commonly made for the estimation of prediction intervals of electricity prices (e.g. Nogales and Conejo, 2006) does not hold. The fact that the spot prices themselves are so far from being Normally distributed will certainly be reflected in the residual distribution of a forecasting model, which parameters are estimated with a least squares criteria. Furthermore, as the price distribution has also been shown to be dependent on an external signal, prediction intervals should be generated accounting for this relation, thus yielding conditional prediction intervals. The analysis therefore indicates that estimating the uncertainty conditioned on an explanatory variable, e.g. wind power forecasts, in a non-parametric fashion could increase the resolution of probabilistic forecasts of electricity spot prices.

In this paper, the scope has been the Western Danish price area (DK1) at Nord Pool. This price area may be seen as representative of the future deregulated electricity with significant penetration of renewable energy generation. Although the share of wind power in DK-1 is larger than anywhere else in the world, it is very plausible that the effects, revealed here, can also be detected in other market areas as well, penetrated by wind power to some extent - for instance in Spain or Germany. Similar causes would have similar effects, the principal ones being varying availability of the fuel and extremely low marginal costs.

The severe impact of wind power forecasts on all behaviour of the electricity prices is also interesting to consider in the context of market design and with the long-term development of the production portfolio in Denmark in mind - where the intention is to increase the share of wind power generation up to $50 \%$ of the electricity consumption by 2025 (Ea Energy Analyses, 2007). With the current market structure of marginal bidding, the frequency of hours where the spot price is zero is bound to increase along with growing wind power penetration in the system in a similar manner as has been demonstrated here. This will further enhance the stochastic threshold effect demonstrated here, and thereby increase price volatility and cause it to have alternating weather dependent patterns (Meibom, 2007). This aside, higher risk premium will be required on investments in all sorts of new energy generation capacity and investment in conventional power generation capacity will be more focused on flexibility than efficiency since those plants will have to rely more on the increased demand on the balance markets as a source of income (Meibom, 2007). The impact of wind power on the price making at the electricity markets should therefore 
be given careful thought when the possibility of increasing the share of wind power, and non-dispatchable energy sources in general, in the generation portfolio is discussed. Especially, the fact that wind power penetration has some non-linear effects on the prices should be taken into consideration, as it implies that current market situation can not be scaled directly for analysing the future circumstances. In the context of market design, it will also be interesting to monitor the market's response to other renewable sources reaching the status of making up for a significant share of the energy supply. Those sources in all likelihood being solar or wave energy in the medium term. Whether this will level out the effect of increased wind power or magnify them will play an important role in future development of the market structure.

\section{Acknowledgements}

The authors would like to thank Energinet.dk, the danish Transmission system operator, and Nord Pool ASA for providing data for the analysis, publicly available at http://www.energinet.dk/en/ menu/Market/Market.htm and at http://www. nordpool spot.com. Authors are also grateful to Henrik Aa. Nielsen at ENFOR A/S for fruitful discussions and useful comments and Torben Skov Nielsen at ENFOR A/S for providing wind power predictions.

\section{References}

Bathurst, G. N., Weatherill, J., Strabac, G., 2002. Trading wind generation in short term energy markets. IEEE Transactions on Power Systems 17(3), 782-89.

Boogert, A., Dupont, D., 2005. On the effectiveness of the anti-gaming policy between the day-ahead and real-time electricity markets in the netherlands. Energy Economics 27(5), 752-770.

Christensen, B. J., Jensen, T. E., Mølgaard, R., 2007. Market power in power markets: Evidence from forward prices of electricity. CREATES Research Paper No. 2007-30. Available at http: / / ssrn.com/ abstract $=1150145$.

Cleveland, W. S., Devlin, S. J., 1988. Locally weighted regression: An approach to regression analysis by local fitting. Journal of the American Statistical Association 83(403), 596-610. 
Conejo, A. J., Contreras, J., Espínola, R., Plazas, M. A., 2005. Forecasting electricity prices for a day-ahead pool-based electric energy market. International Journal of Forecasting 21(3), 435-462.

Costa, A., Crespo, A., Navarro, J., Lizcano, G., Madsen, H., Feitona, E., 2008. A review on the young history of wind power short-term prediction. Renewable \& Sustainable Energy Reviews 12(6), 17251744 .

Cuaresma, J. C., Hlouskova, J., Kossmeier, S., Obersteiner, M., 2004. Forecasting electricity spot-prices using linear univariate time-series models. Applied Energy 77(1), 87-106.

Daneshi, H., Daneshi, A., April 2008. Price forecasting in deregulated electricity markets - a bibliographical survey. In: The 3rd IEEE International Conference on Electric Utility Deregulation, Restructuring, and Power Technology (DRPT2008). Nanjing, China.

Ea Energy Analyses, 2007. 50\% wind power in denmark in 2025 english summary. Available at: http://www.talentfactory.dk/ media $(2513,1033) / 081029$ 50pct._wind_power_ion_dk_in_ 2025.pdf.

Eggertsson, H., 2003. The scandinavian elecricity power market and market power. Master's thesis, Technical University of Denmark, DTU, Kgs. Lyngby, Denmark, available at http: //www2.imm.dtu . $\mathrm{dk} /$ pubdb/views/publication_details.php?id=2533.

Enevoldson, S. W., Østergaard, P. A., Morthorst, P. E., Moesgaard, R., 2006. Vindkraftens betydning for elprisen i danmark. Tech. rep., IBTWind, in Danish.

Giabardo, P., Zugno, M., 2008. Competitive bidding and stability analysis in electricity markets using control theory. Master's thesis, Informatics and Mathematical Modeling, Technical University of Denmark, DTU, Kgs. Lyngby, Denmark, available at www2 . imm. dtu . dk / $\sim$ pp/thesis.htm.

Giabardo, P., Zugno, M., Pinson, P., Madsen, H., 2009. Feedback, competition and stochasticity in a day ahead electricity market. Energy Economics Available online. 
Giebel, G., Kariniotakis, G., Brownsword, R., 2003. The stateof-the-art in short-term prediction of wind power - a literature overview. EU project Anemos, Deliverable Report D1.1, Available at http://anemos.cma.fr/download/ANEMOS_D1.1_ StateofTheArt_v1.1.pdf.

González, A. M., Roque, A. M. S., García-González, J., 2005. Modeling and forecasting electricity prices with input/output hidden markov models. IEEE Transactions on Power Systems 20(1), 13-24.

Huisman, R., Huurman, C., Mahieu, R., 2006. Hourly electricity prices in day-ahead markets. Energy Economics 29(2), 240-248.

Jónsson, T., 2008. Forecasting of electricity prices accounting for wind power predictions. Master's thesis, Informatics and Mathematical Modeling, Technical University of Denmark, DTU, Kgs. Lyngby, Denmark.

Karakatsani, N. V., Bunn, D. W., 2008. Forecasting electricity prices: The impact of fundamentals and time-varying coefficients. International Journal of Forecasting 24(4), 764-785.

Kosater, P., Mosler, K., 2006. Can Markov regime-switching models improve power-price forecasts? Evidence from German daily power prices. Applied Energy 83(9), 943-958.

Longstaff, F. A., Wang, A. W., 2004. Electricity forward prices: A highfrequency empirical analysis. The Journal of Finance 59(4), 18771900 .

Madsen, H., Holst, J., 2000. Modelling Non-Linear and Non-Stationary Time Series (Lecture Notes). IMM, DTU, Kgs. Lyngby, Denmark.

Mandal, P., Senjyu, T., Funabashi, T., 2006. Neural networks approach to forecast several hour ahead electricity prices and loads in deregulated markets. Energy Conversion \& Management 47(15-16), 21282142 .

Matevosyan, J., Söder, L., 2006. Minimization of imbalance cost trading wind power on the short-term power market. IEEE Transactions on Power Systems 21(3), 1396-1404.

Meibom, P., 2007. Market consequences [in my view]. IEEE Power and Energy Magazine 5(6), 120-118. 
Moesgaard, R., Morthorst, P. E., April 2008. The impact of wind power on electricity prices in denmark. In: EWEC 2008, European Wind Energy Conference, Business and Policy Track. Brussels, Belgium.

Møller, J. K., Nielsen, H. A., Madsen, H., 2008. Time-adaptive quantile regression. Computational Statistics and Data Analysis 52(3), 12921303.

Morthorst, P. E., 2003. Wind power and the conditions at a liberalized power market. Wind Energy 6(3), 297-308.

Nielsen, H. A., Nielsen, T. S., Joensen, A. K., Madsen, H., Holst, J., 2000. Tracking time-varying coefficient functions. International Journal of Adaptive Control and Signal Processing 14(8), 813-828.

Nielsen, T. S., Nielsen, H. A., Madsen, H., 2002. Prediction of wind power using time-varying coefficient functions. In: 15th IFAC World Congress. Barcelona, Spain.

Nogales, F., Conejo, A. J., 2006. Electricity price forecasting through transfer function models. Journal of Operational Research Society 57(3), 350-356.

Nord Pool Spot AS, 2006a. Bidding in Nord Pool Spot's Elspot Market. Available at www. nordpoolspot.com.

Nord Pool Spot AS, 2006b. Calculation of System- and Area prices. Available at www. nordpoolspot.com.

Panagiotelis, A., Smith, M., 2008. Bayesian density forecasting of intraday electricity prices using multivariate skew t distributions. International Journal of Forecasting 24(4), 710-727.

Pinson, P., Chevallier, C., Kariniotakis, G. N., 2007. Trading wind generation from short-term probabilistic forecasts of wind power. IEEE Transactions on Power Systems 22 (3), 1148-1156.

Ruibal, C. M., Mazumdar, M., 2008. Forecasting the mean and the variance of electricity prices in deregulated markets. IEEE Transactions on Power Systems 23 (1), 25-32.

Schwarz, H.-G., Lang, C., Meier, S., 2007. Market power in the german wholesale electricity market: What are the political options? Available at SSRN, http://ssrn.com/abstract $=1028201$. 
Sewalt, M., de Jong, C., 2003. Negative prices in electricity markets. Commodities Now. Available at http://www.erasmusenergy. com/articles/91/1/Negative-prices-in-electricio ty-markets/Pagel.html.

Skytte, K., 1999. The regulating power market on the nordic power exchange nord pool: an econometric analysis. Energy Economics 21(4), 295-308.

Taylor, J. W., McSharry, P. E., 2007. Short-term load forecasting methods: An evaluation based on european data. IEEE Transactions on Power Systems 22(4), 2213-2219.

Vehviläinen, I., Pyykkönen, T., 2005. Stochastic factor model for electricity spot price - the case of the nordic market. Energy Economics 27(2), 351-367. 